\title{
RENÉ 65 BILLET MATERIAL FOR FORGED TURBINE COMPONENTS
}

\author{
Betsy J. Bond ${ }^{1}$, Christopher M. O'Brien ${ }^{1}$, Jeffrey L. Russell ${ }^{1}$ \\ Joseph A. Heaney ${ }^{2}$, Michael L. Lasonde ${ }^{2}$ \\ ${ }^{1}$ ATI Specialty Materials; 2020 Ashcraft Ave, Monroe, NC 28110, USA \\ ${ }^{2}$ General Electric Aviation; One Neumann Way; Cincinnati, Ohio, 45215, USA
}

Keywords: René 65, Superalloy, Forgeability, Nickel-base, Cast and Wrought

\begin{abstract}
ATI Specialty Materials has collaborated with General Electric Aviation in the development of René 65, a highly alloyed gamma-prime strengthened nickel-base superalloy produced using advanced ingot metallurgy practices to develop a uniform fine-grain microstructure for disk and ring applications. This paper addresses the key product characteristics of René 65 billet including grain structure, thermal response and microcleanliness. Billet hot workability is presented as well as ultrasonic capability of the billet.
\end{abstract}

\section{Introduction}

René 65 is a precipitation hardenable nickel-base superalloy developed through collaboration between General Electric Aviation and ATI Specialty Materials. The alloy is a cast and wrought derivative of René $88 \mathrm{DT}^{1}$, a General Electric powder metallurgy alloy used for rotating jet engine applications. Whereas René 88DT is only forgeable to disk configurations in an isothermal press, René 65 can also be processed using conventional hot-die forging and ringrolling methods. Nominal chemistries in weight percent for René 65 and other cast/wrought superalloys used for disk application are shown below in Table I. The amount of gamma prime is about 40 volume percent.

Table I: Nominal Compositions of René 65 and Other Ni-base Superalloys (Weight Percent)

\begin{tabular}{|c|c|c|c|c|c|c|c|c|c|c|c|}
\hline & $\mathrm{Ni}$ & $\mathrm{Cr}$ & $\mathrm{Mo}$ & $\mathrm{W}$ & $\mathrm{Co}$ & $\mathrm{Fe}$ & $\mathrm{Nb}$ & $\mathrm{Ti}$ & $\mathrm{Al}$ & $\mathrm{Zr}$ & $\mathrm{B}$ \\
\hline René 65 & Bal. & 16 & 4 & 4 & 13 & 1 & 0.7 & 3.7 & 2.1 & 0.05 & 0.016 \\
\hline Waspaloy & Bal. & 19.4 & 4.25 & - & 13.25 & - & - & 3 & 1.3 & 0.05 & 0.006 \\
\hline ATI 718 Plus & Bal. & 18 & 2.8 & 1 & 9 & 10 & 5.4 & 0.7 & 1.45 & - & 0.006 \\
\hline 718 & Bal. & 18.1 & 2.9 & - & - & 18 & 5.4 & 1 & 0.45 & - & - \\
\hline Alloy 720 & Bal. & 16 & 3 & 1.25 & 15 & - & - & 5 & 2.5 & 0.03 & 0.015 \\
\hline
\end{tabular}

Consistent with applicable General Electric specifications, René 65 ingots are produced by a triple melt practice of Vacuum Induction Melting (VIM), followed by Electroslag Remelting (ESR) and Vacuum Arc Remelting (VAR) operations. ${ }^{2}$ The ingot produced by intermediate ESR provides a solid electrode for VAR which helps optimize stability of melt parameters such as melt rate during VAR. Production ingots are $508 \mathrm{~mm}$ (20-inch) in diameter with larger ingot sizes under development. The ingots are homogenized and forged by ATI Specialty Materials on an open-die hydraulic press followed by radial forging to billet of various diameters. 


\section{Low Interstitial History}

In the initial phases of the development program, carbon and nitrogen contents were set at levels that were considered appropriate for mechanical properties and metallographic microcleanliness. While monotonic mechanical properties met program requirements, low-cycle fatigue life was lower than desired. Analysis of the LCF fracture surfaces showed that low-life specimens displayed carbo-nitrides at the crack initiation sites. Furthermore, the billet microstructure tended to show a relatively high area fraction of carbo-nitride stringers. These observations and studies reported in the literature ${ }^{3}$ prompted evaluating chemistry aims for interstitial elements. A matrix of subscale VIM/VAR ingots $150 \mathrm{~mm}$ (6-inch) in diameter were processed to help optimize the carbon and nitrogen levels. This led to establishing an LI (Low Interstitial) version of René 65 . Figures $1 \mathrm{a}$ and $1 \mathrm{~b}$ illustrate typical unetched microstructures for the LI and Non-LI versions. The typical field of LI shown in Figure 1a is extremely clean with isolated particles that are primarily nitrides and occasionally carbo-nitrides and rarely carbides.
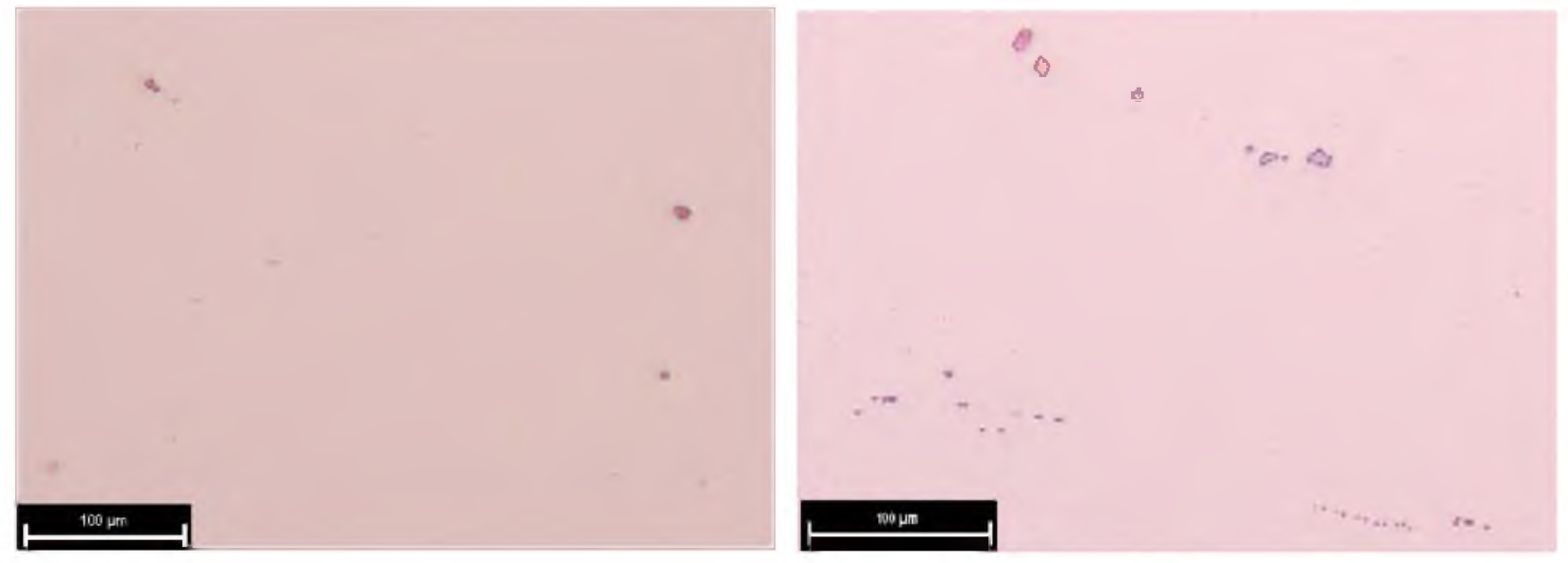

Figures $1 \mathrm{a}$ and $1 \mathrm{~b}$. Typical Unetched Microstructures for LI and Non-LI Versions of René 65

The typical structure for Non-LI shown in Figure lb contains a higher density of nitrides, carbides and carbo-nitrides and reveals a tendency to form stringers. Figure 2 shows the particles at the top of Figure $1 \mathrm{~b}$ at a higher magnification.

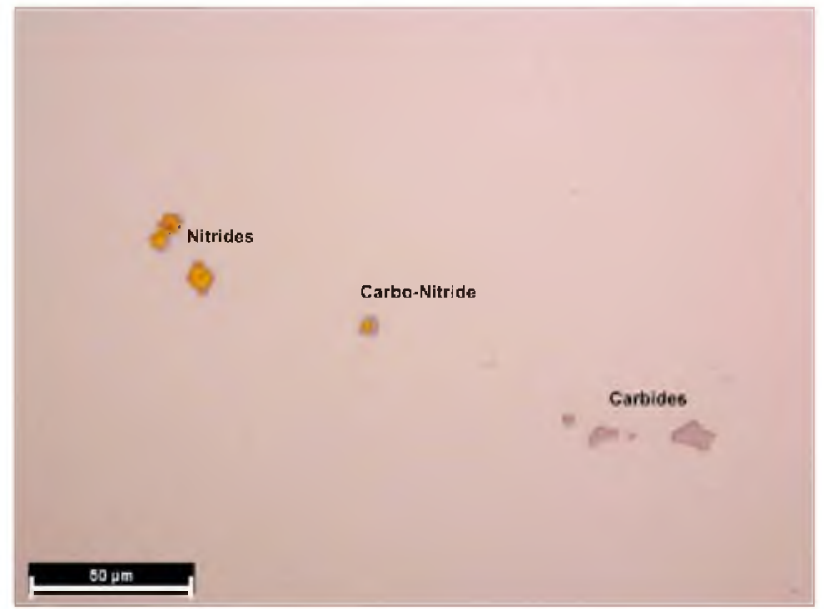

Figure 2. Higher Magnification of Particles in Figure $1 b$. 
The nitride particles are readily recognized by their orange color while carbides appear gray. EDS spectra are presented in Figure $3 \mathrm{a}$ and $3 \mathrm{~b}$ for nitrides and carbides. Nitrides are TiN; carbides are enriched in titanium and niobium and contain some tungsten and molybdenum. Nitrides, carbides, and carbo-nitrides are usually about $12 \mu$ or less.
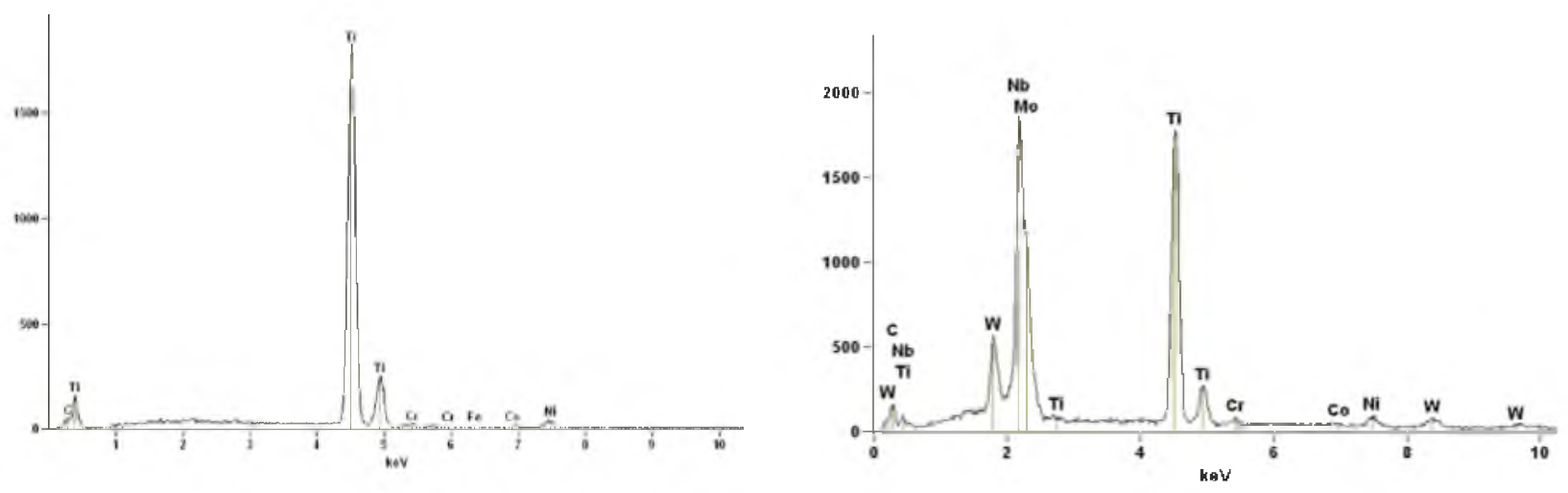

Figures 3a and 3b. EDS Spectra for Nitrides(a) and Carbides(b) Found in René 65

Subsequent testing confirmed that LCF life was considerably improved with the low interstitial (LI) chemistry as shown below in Figure $4{ }^{4}$ The $Z$ values reflect the number of standard deviations from expected average behavior with the non-LI (low interstitial) tests approximately $.8 \mathrm{Z}$ lower in fatigue capability compared to LI tests.

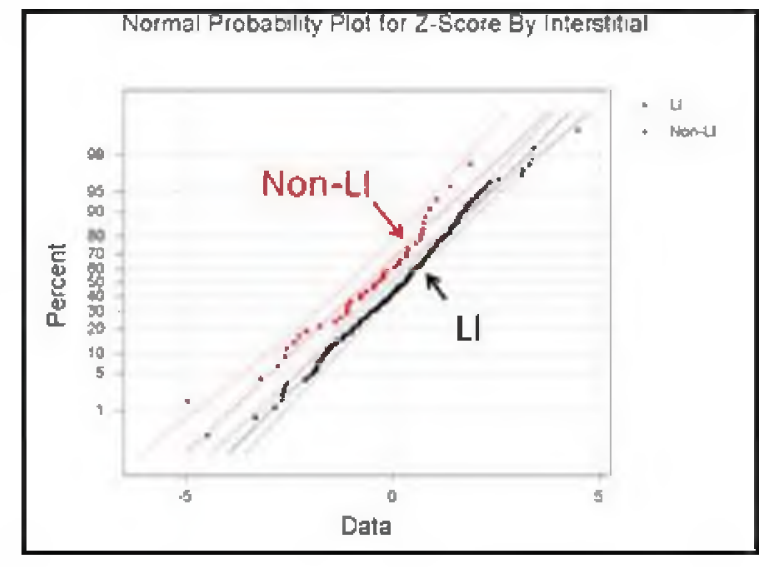

Figure 4. Effect of Interstitial Level on Fatigue Capability ${ }^{3}$

\section{Billet Microstructure}

Effective forging practices convert the large as-cast ingot grains to a fine matrix grain size. Figure 5 shows typical grain structures of $254 \mathrm{~mm}$ (10-inch) diameter René 65 billet at the surface, mid-radius and center positions. The etchant used was Modified Kallings, which consists of 12 grams of $\mathrm{CuCl}_{2}, 10 \mathrm{ml}$ of distilled water and $120 \mathrm{ml} \mathrm{HCl}$.

The structure at the surface of the billet is very fine grained (ASTM 10-12) as shown in Figure $5 \mathrm{a}$. The microstructures shown in Figure 5 are as-forged, as are all the microstructures in this report except those in the section on thermal exposure. The isolated darker etching region evident in Figure 5a is fine grained as shown at a higher magnification in Figure 5b. Relative to the surrounding matrix, the darker etching area has a finer grain size and finer $\gamma^{\prime}$ particles. This is 
further revealed in Figure 6 which is a higher magnification of Figure $5 \mathrm{~b}$. The red particles in Figure 6 represent $\gamma^{\prime}$ particles used to determine the primary $\gamma^{\prime}$ size by image analysis in the dark etching region $(1.3 \mu)$ and in the surrounding matrix $(2.9 \mu)$.
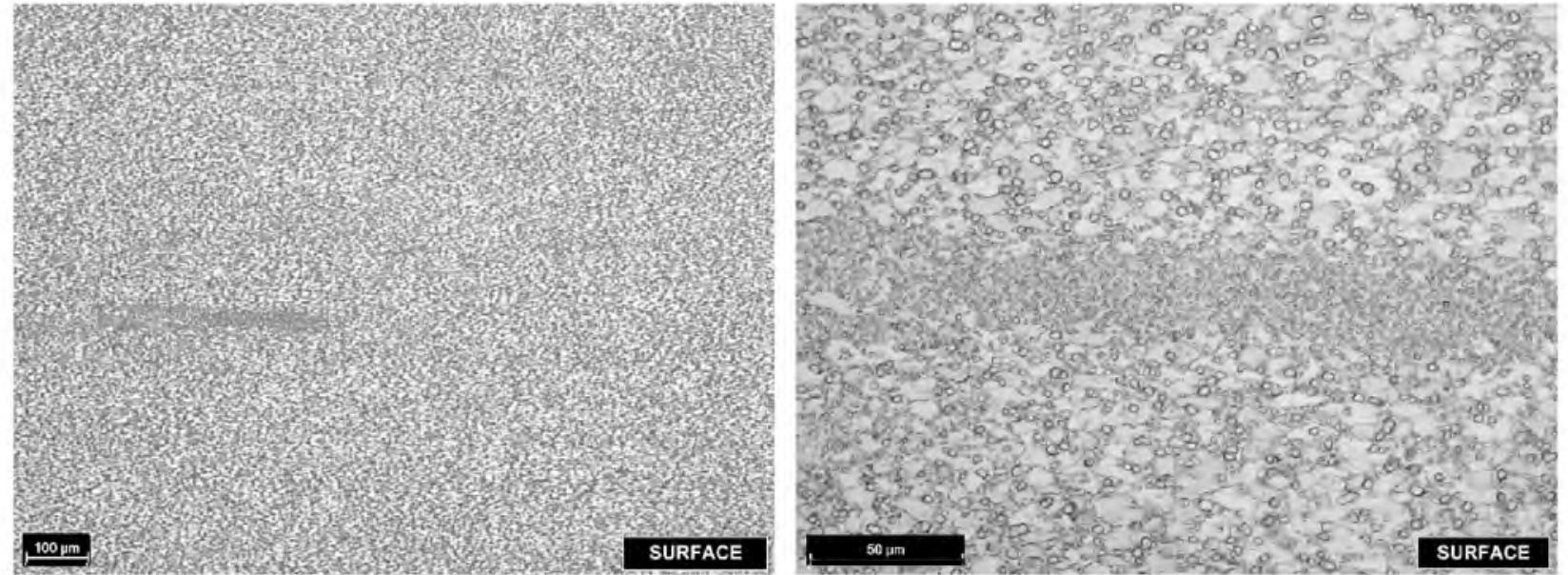

René 65 Billet Surface (a) Originally 100X

René 65 Billet Surface (b) Originally 500X
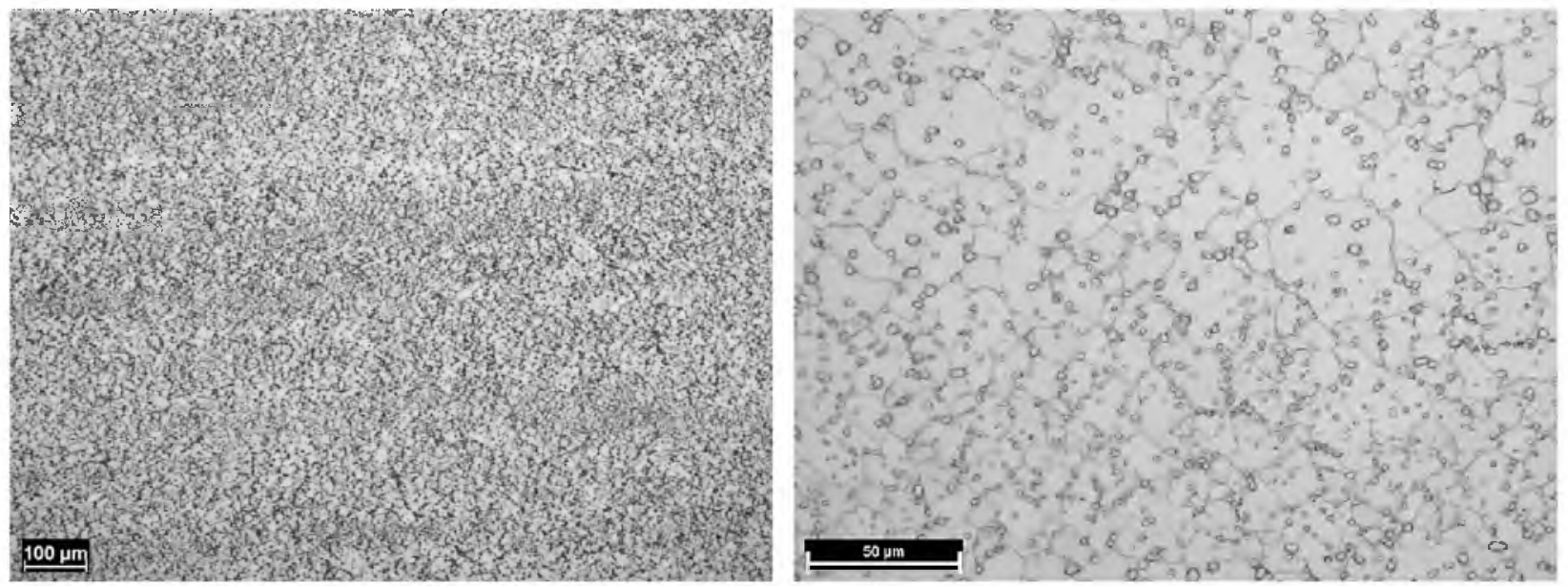

René 65 Billet Mid-Radius (c) Originally 100X

René 65 Billet Mid-Radius (d) Originally 500X
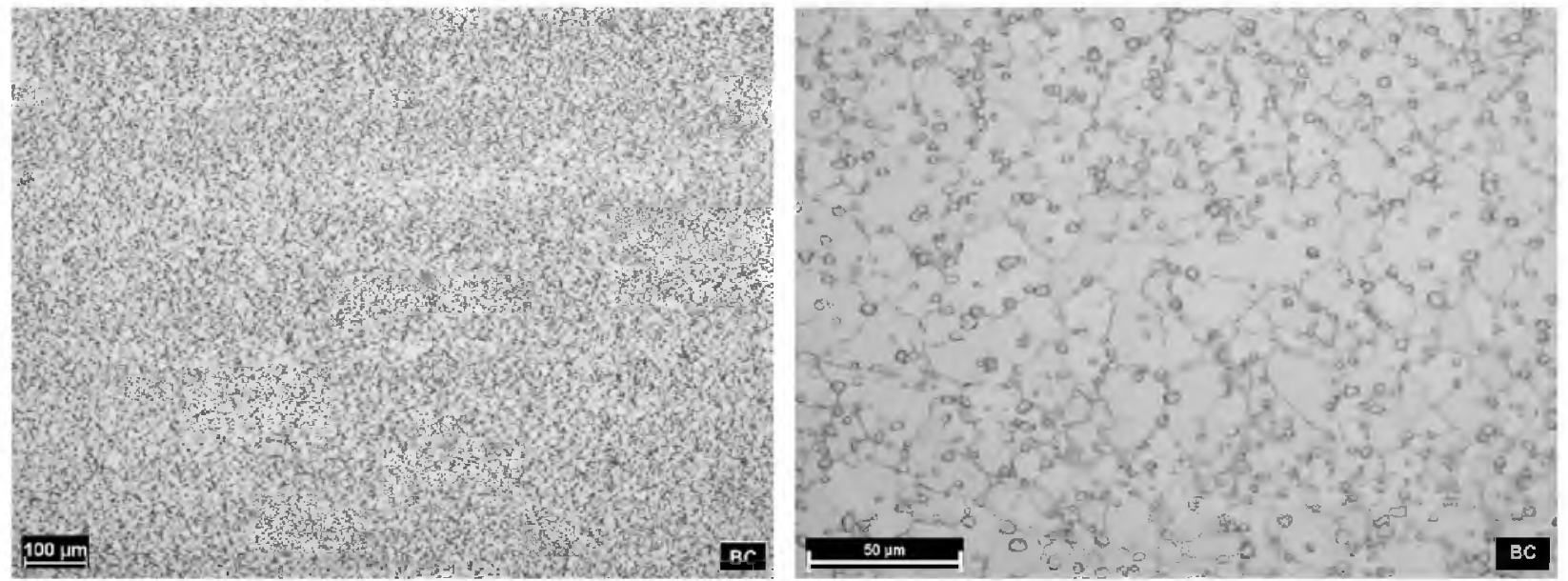

René 65 Billet Center (e) Originally 100X

René 65 Billet Center (f)

Originally $500 \mathrm{X}$

Figure 5. As-Forged Microstructures for a $254 \mathrm{~mm}$ Dia. Billet 

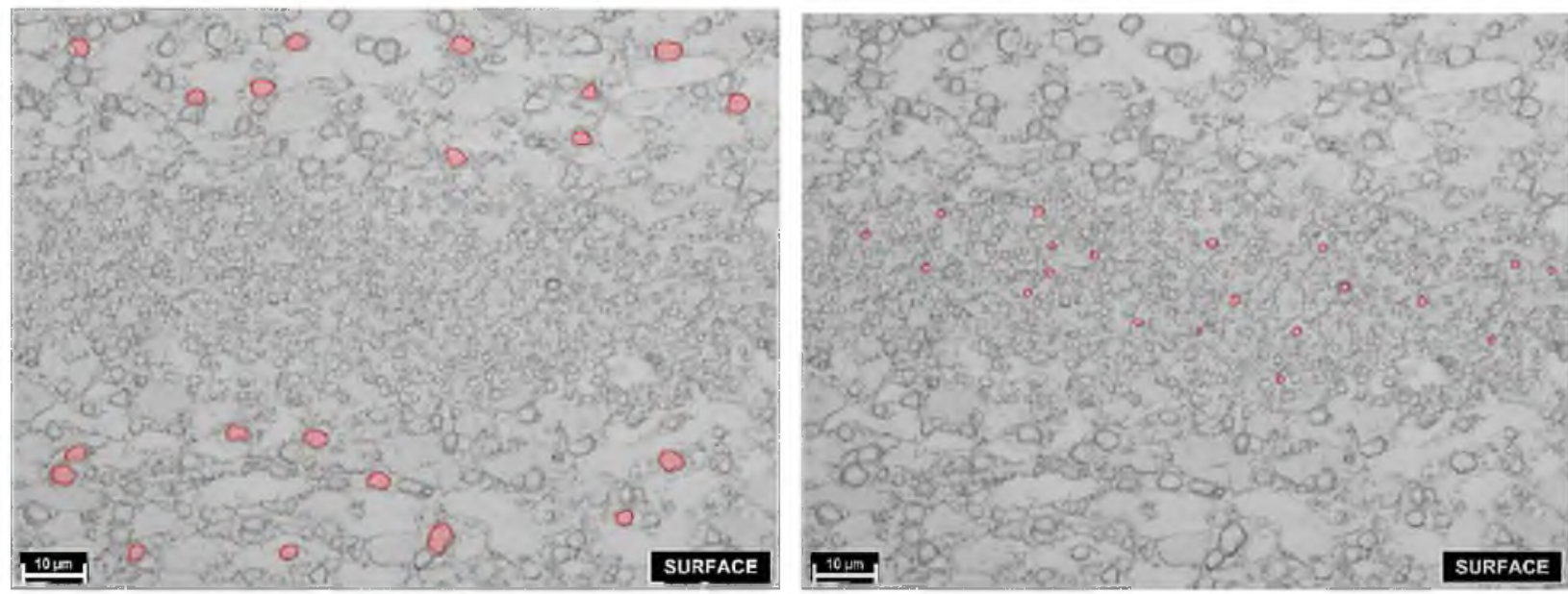

Figure 6. Higher Magnification of $\gamma^{\prime}$ Particles in Light and Dark-Etching Regions of Figure $5 \mathrm{~b}$

The darker etching regions represent former unrecrystallized grains that recrystallized late in the billet conversion process. With further deformation, they eventually disappear as the $\gamma^{\prime}$ continue to grow to the same size as the surrounding matrix. They are more predominant in the surface structures but also can be present in interior locations. Microprobe analysis has indicated that there is no difference in chemistry between the matrix and the darker etching regions.

Interior (sub-surface) microstructures are typically ASTM 8-10, but always ASTM 7 or finer. Typical mid-radius and center billet microstructures are shown in Figure 5(c-f). It can be seen that microstructures are similar for these locations. Each exhibits slight variations in etching response with lightly etched locations exhibiting slightly lower $\gamma^{\prime}$ densities which can result in slight grain size variations. This characteristic is typical for high strength cast/wrought superalloys. Primary $\gamma^{\prime}$ diameter was measured by image analysis to be $3.0 \mu$ for the typical $\gamma^{\prime}$ distribution in Figure 7 for a mid-radius location. The red particles in Figure 7 represent $\gamma^{\prime}$ particles used to determine the $\gamma^{\prime}$ size by image analysis.
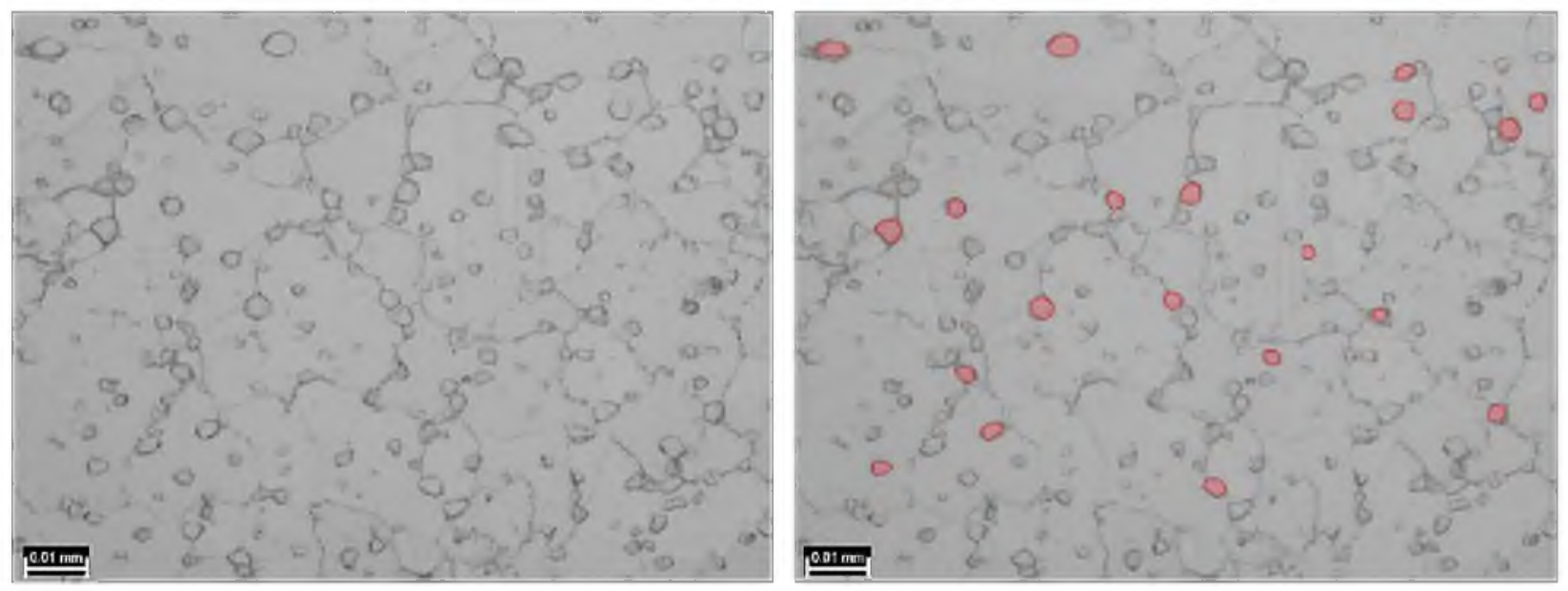

Figure 7. Gamma Prime Particles in Billet Microstructure of $254 \mathrm{~mm}$ Dia. Billet

Unrecrystallized grains are occasionally present in the billet microstructure. They generally appear as light etching areas as shown in Figure 8. Hardness measurements on unrecrystallized 
grains have displayed no significant difference in hardness between the unrecrystallized grains and the nearby matrix. This is illustrated in Figure 8 . Vickers values obtained by microhardness measurements were converted to Rockwell $\mathrm{C}$ hardness numbers. An investigation on the effect of unrecrystallized grains on low cycle fatigue (LCF) did not find any negative influence on LCF results. ${ }^{4}$ The effects of strain, strain rate and temperature on eliminating unrecrystallized grains have been investigated. ${ }^{5}$

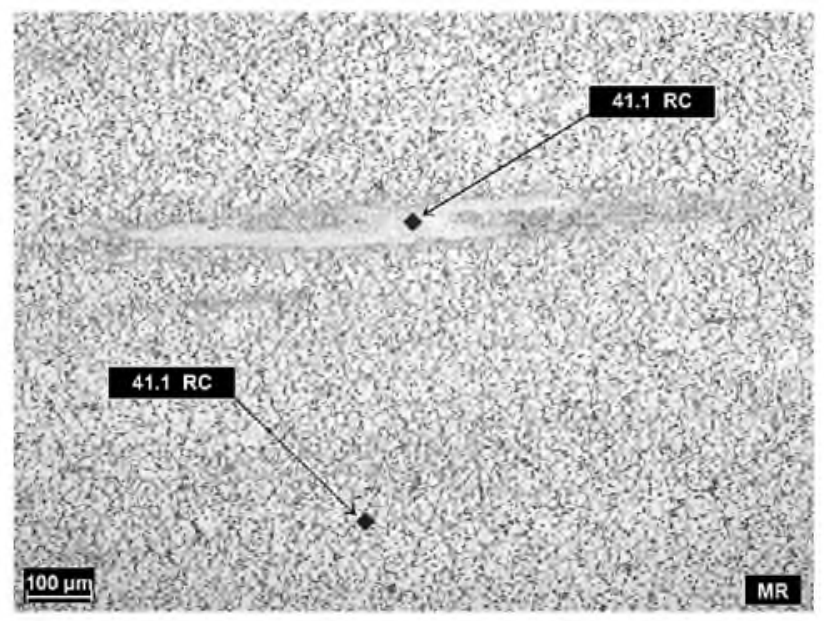

Figure 8. Typical Unrecrystallized Grain with Hardness Value Relative to the Matrix

A typical unetched microstructure is shown in Figure 9.

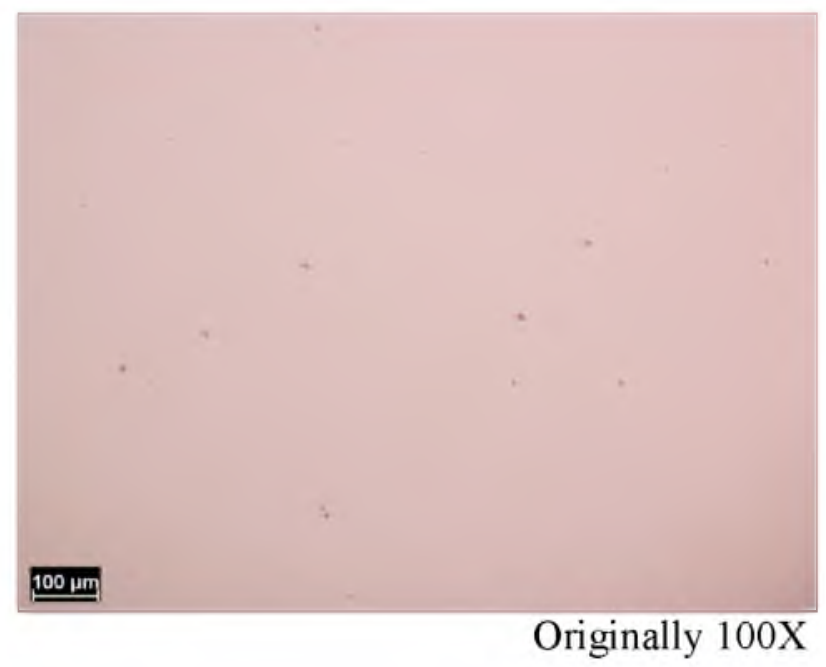

Figure 9. Unetched Microstructure for $254 \mathrm{~mm}$ Dia. Billet

While the LI composition virtually eliminated the presence of carbide stringers in Rene 65 microstructure, the alloy does contain a relatively low level of titanium nitride stringers that may also occasionally contain individual carbide or carbo-nitride particles. These TiN stringers are evaluated using a method developed by ATI Specialty Materials expressly for René 65 to further insure that the microstructural condition associated with lower than desired LCF life will be avoided. This evaluation method involves classifying the observed stringers by length and tabulating their frequency to produce an aggregate rating. An example of a stringer is shown in 
Figures $10 \mathrm{a}$ and $10 \mathrm{~b}$. Figure $10 \mathrm{~b}$ shows the stringer in $10 \mathrm{a}$ at a higher magnification. Optical micrographs were taken in color to highlight the orange nitride particles. It can be seen that the stringer is comprised primarily of nitrides with a few carbo-nitride particles.
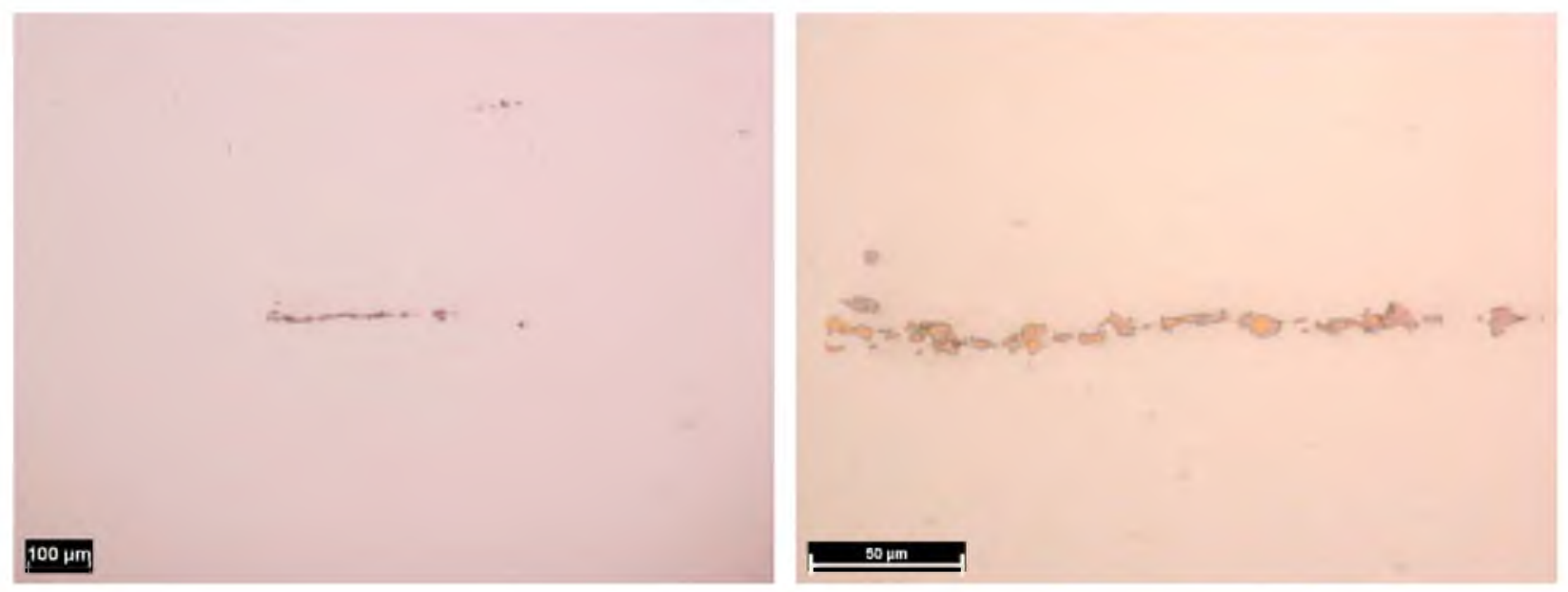

Figure 10a and 10b. Example of a Stringer in René 65

Since René 65 contains a relatively high level of boron, borides are commonly seen in the microstructure. These borides, which are very small compared with typical nitride particles, appear as round/oval white particles in SEM backscatter images as shown in Figure 11. Figure 11 also shows a typical boride EDS spectrum. The borides are enriched in $\mathrm{Mo}, \mathrm{W}$, and $\mathrm{Cr}$ with some $\mathrm{Ti}$ and $\mathrm{Nb}$ present.

panm

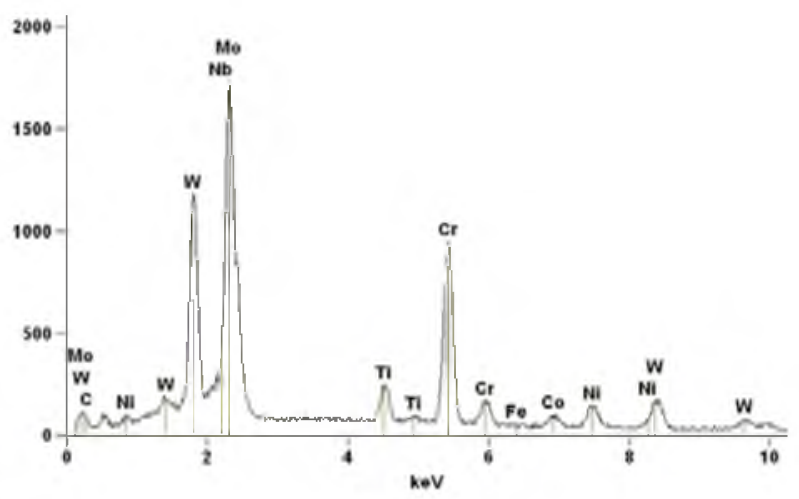

Figure 11. Typical Borides (White) Found in René 65 with Associated EDS Spectrum. Dark Particles in the Background are $\gamma^{\prime}$

\section{Grain Size Coarsening with Thermal Exposure}

René 65 billet response to high temperature exposures is typical of cast/wrought superalloys that are precipitation strengthened. Specifically, the as-forged grain structure remains uniform and fine until a critical temperature is reached where the structure begins to display local coarsening to a duplex grain structure. For René 65 , this critical temperature is approximately $1085 \mathrm{C}$ 
(1985F) for a 1 hour or greater soak time. The structure shows additional incremental coarsening as the $\gamma^{\prime}$ solvus temperature is approached. Actual data for one hour exposures generated on $254 \mathrm{~mm}$ (10-inch) diameter billet are shown below in Table II and graphically in Figure 12. Corresponding photomicrographs of thermally exposed billet microstructures are shown in Figure 13.

Table II. Grain Size Data as a Function of Exposure Temperature for 1-Hour, $254 \mathrm{~mm}$ Dia. Billet

\begin{tabular}{|c|c|c|c|c|c|}
\hline $\begin{array}{c}\text { Temperature } \\
(\mathrm{C})\end{array}$ & $\begin{array}{c}\text { Temperature } \\
(\mathrm{F})\end{array}$ & $\begin{array}{c}\text { Average } \\
\text { Grain Size }\end{array}$ & $\begin{array}{c}\text { Fine Grain } \\
\text { Size }\end{array}$ & $\begin{array}{c}\text { Coarse } \\
\text { Grain Size }\end{array}$ & $\begin{array}{c}\% \\
\text { Coarse }\end{array}$ \\
\hline 1052 & 1925 & 9.5 & --- & --- & 0 \\
\hline 1066 & 1950 & 9.5 & --- & --- & 0 \\
\hline 1079 & 1975 & 8.5 & --- & --- & 0 \\
\hline 1088 & 1990 & 9 & 9 & 6 & 3 \\
\hline 1093 & 2000 & 8.4 & 8.5 & 5 & 10 \\
\hline 1104 & 2020 & 6.8 & 9 & 3.5 & 80 \\
\hline 1116 & 2040 & 3.5 & --- & 3.5 & 100 \\
\hline
\end{tabular}

The data shown are typical for the alloy, but the degree of coarsening for a given temperature in the transition range (1085 to $1116 \mathrm{C})$ can vary by location within a given billet. For reference, a Differential Thermal Analysis (DTA) plot showing the René $65 \gamma^{\prime}$ solvus temperature $(1111 \mathrm{C} / 2032 \mathrm{~F})$ is presented in Figure 14.

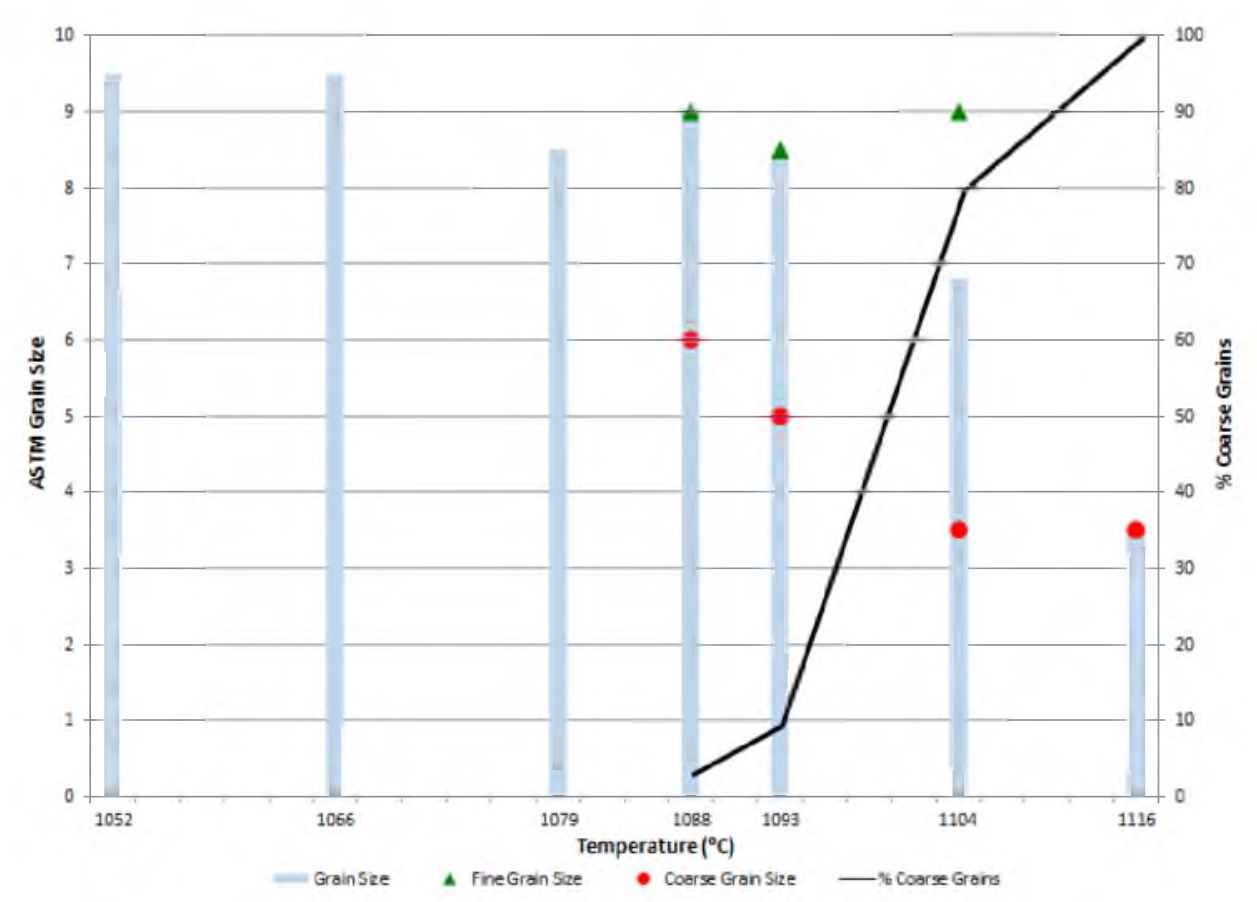

Figure 12. Effect of Exposure Temperature on Grain Size of René 65 for a 1-Hour Exposure at Temperature 


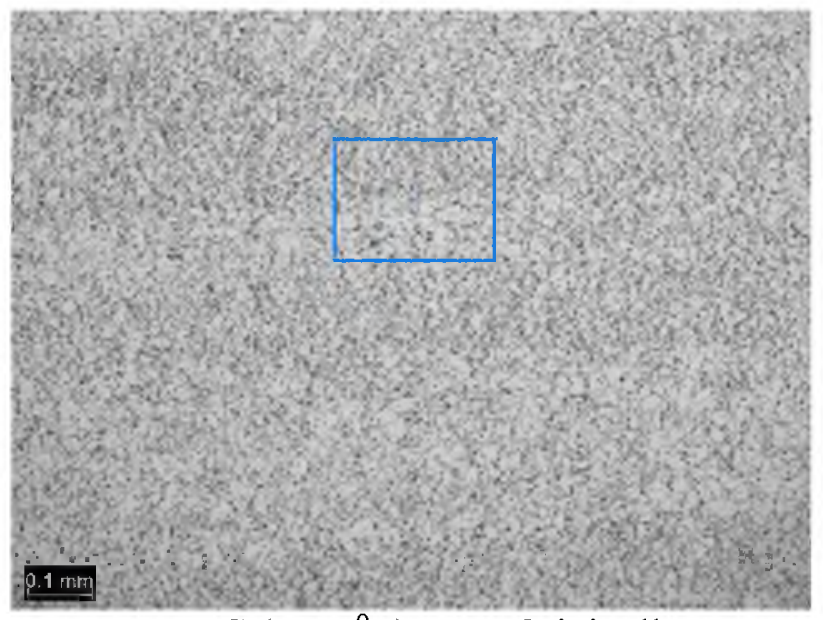

$1088 \mathrm{C}\left(1990^{\circ} \mathrm{F}\right) \quad$ Originally $100 \mathrm{X}$
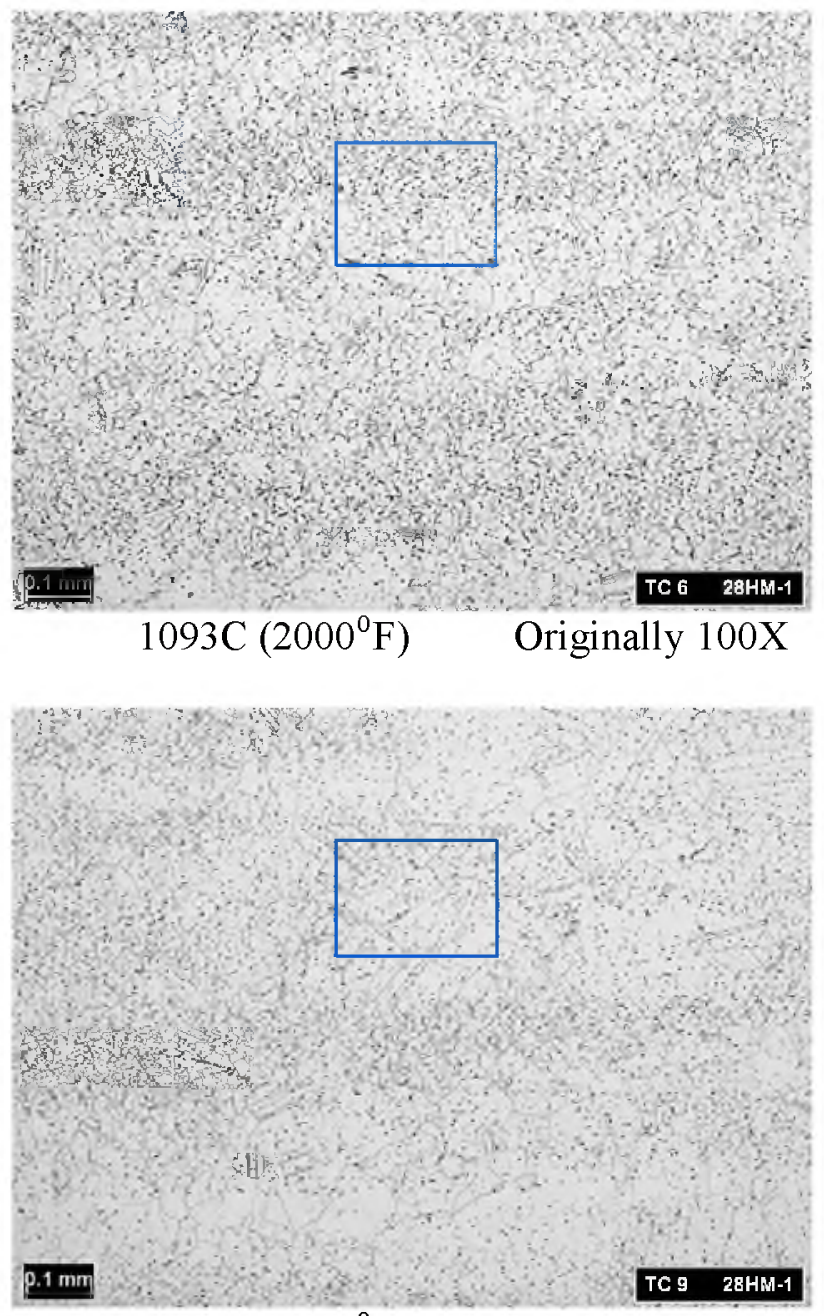

$1104 \mathrm{C}\left(2020^{\circ} \mathrm{F}\right) \quad$ Originally $100 \mathrm{X}$

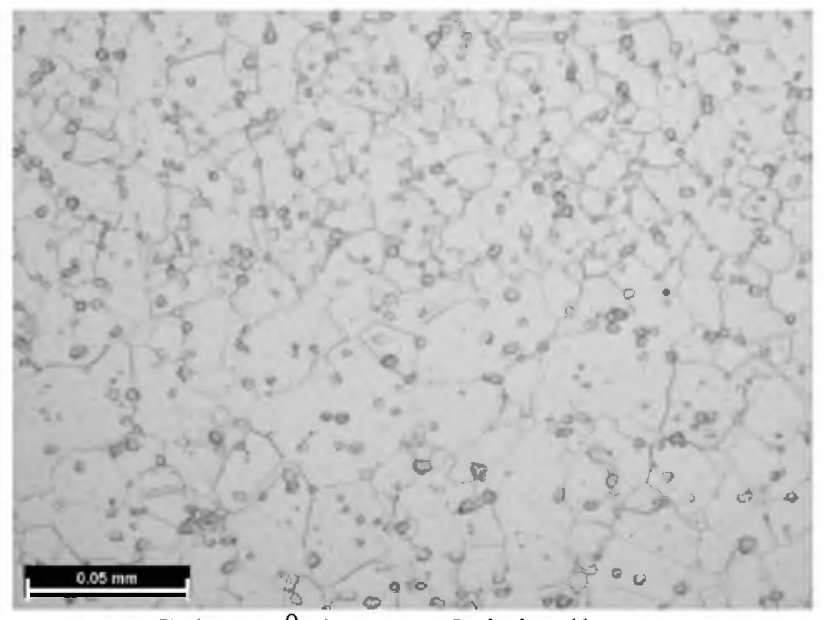

$1088 \mathrm{C}\left(1990^{\circ} \mathrm{F}\right) \quad$ Originally $500 \mathrm{X}$
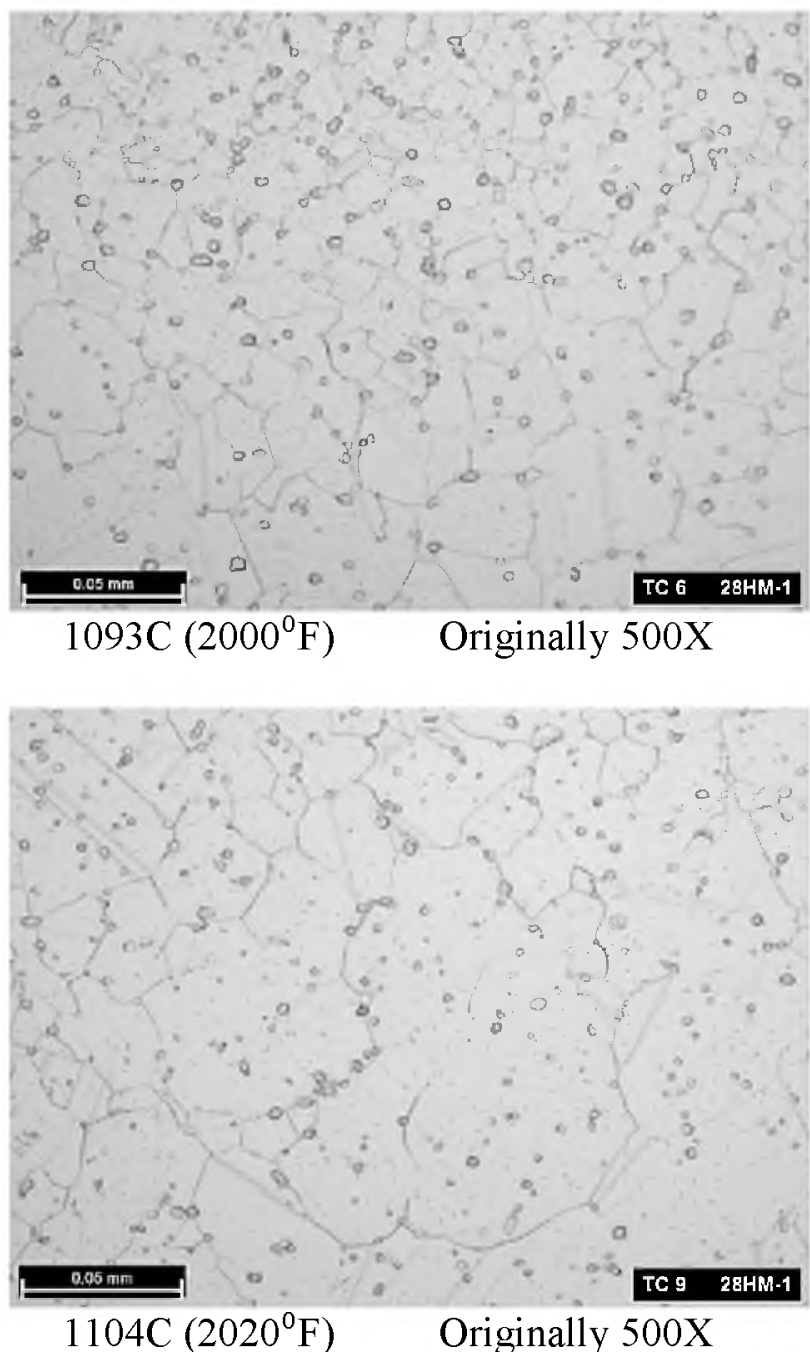

Figure 13. Microstructures of Thermally Exposed Samples at Three Temperatures in the Transition Zone 


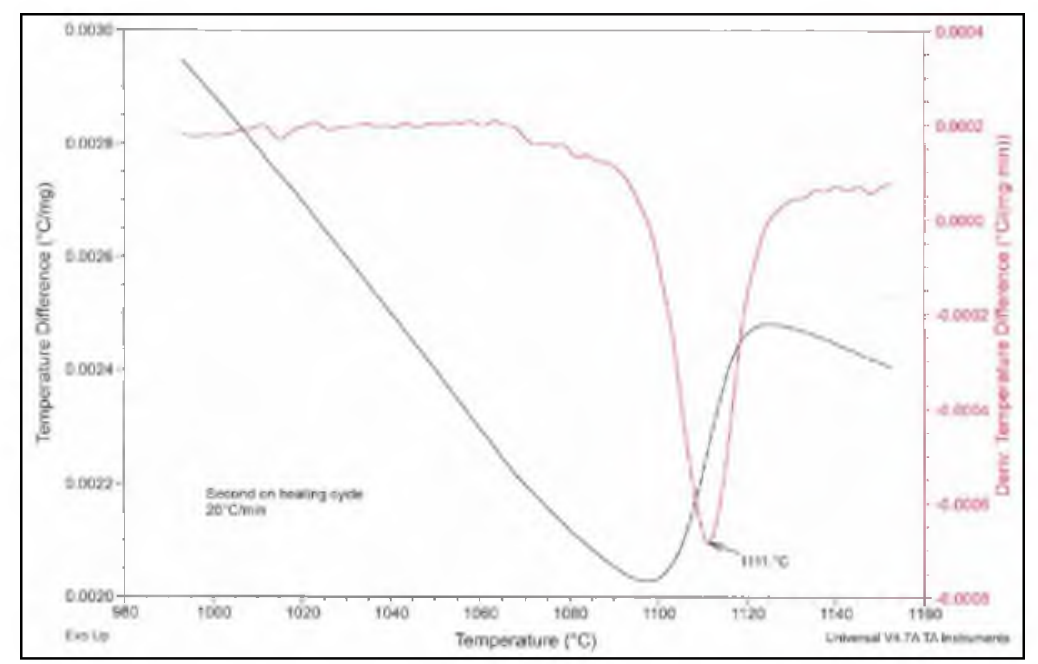

Figure 14. DTA Trace to Determine $\gamma^{\prime}$ Solvus (1111C) of René 65

\section{Billet Ultrasonic Noise}

After hot working the billet is peeled and polished to a suitable surface finish to allow conventional immersion ultrasonic inspection to the requirements specified by General Electric. The ultrasonic noise for René 65 at $250 \mathrm{~mm}$ (10-inch) diameter is typically $15 \%$ to a $0.8 \mathrm{~mm}$ diameter (\#2) flat bottom hole, similar to TM 718 fine grain billet. However, when compared to other high volume fraction gamma-prime strengthened alloys such as Alloy 720 or Waspaloy, René 65 shows a remarkably transparent structure enabling a relatively sensitive billet inspection.

\section{Billet Hot Workability Characteristics}

To aid in identifying appropriate thermomechanical processing parameters, a series of on-heating and on-cooling high temperature rapid strain rate tensile tests were conducted on specimens machined from René 65 billet; percent reduction in area and ultimate tensile strength are shown in Figures 15 and 16. The cross-head speed for these tests was $127 \mathrm{~mm} / \mathrm{min}(5 \mathrm{in} / \mathrm{min})$ and the gauge length was $25.4 \mathrm{~mm}$. The black line in each figure represents on-heating data, where the specimen is simply heated to the test temperature; such data corresponds to the furnace temperature in a component forging operation. The other lines represent on-cooling data to simulate cooling from the furnace temperature. These specimens have been heated as specified in the legend and subsequently air cooled to room temperature; individual specimens were then reheated to the indicated test temperature. On cooling tests exhibit lower ductility and higher strength relative to the on heating tests. This is because $\gamma^{\prime}$ goes into solution on heating and precipitates out as fine $\gamma^{\prime}$ on cooling. Actual results will vary with different test conditions such as strain rate, specimen geometry and heating methods, but should serve as a guide to determining a forging practice. 


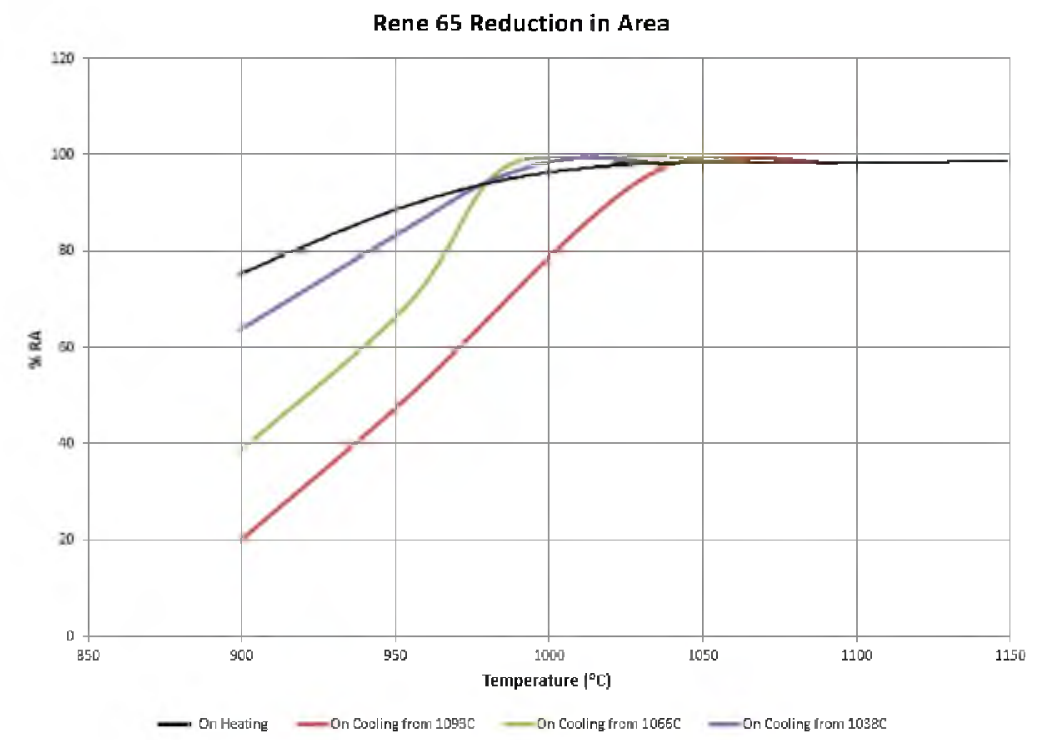

Figure 15. Percent Reduction in Area for On Heating and On Cooling Rapid Strain Rate Tests on $254 \mathrm{~mm}$ Dia. Billet of René 65

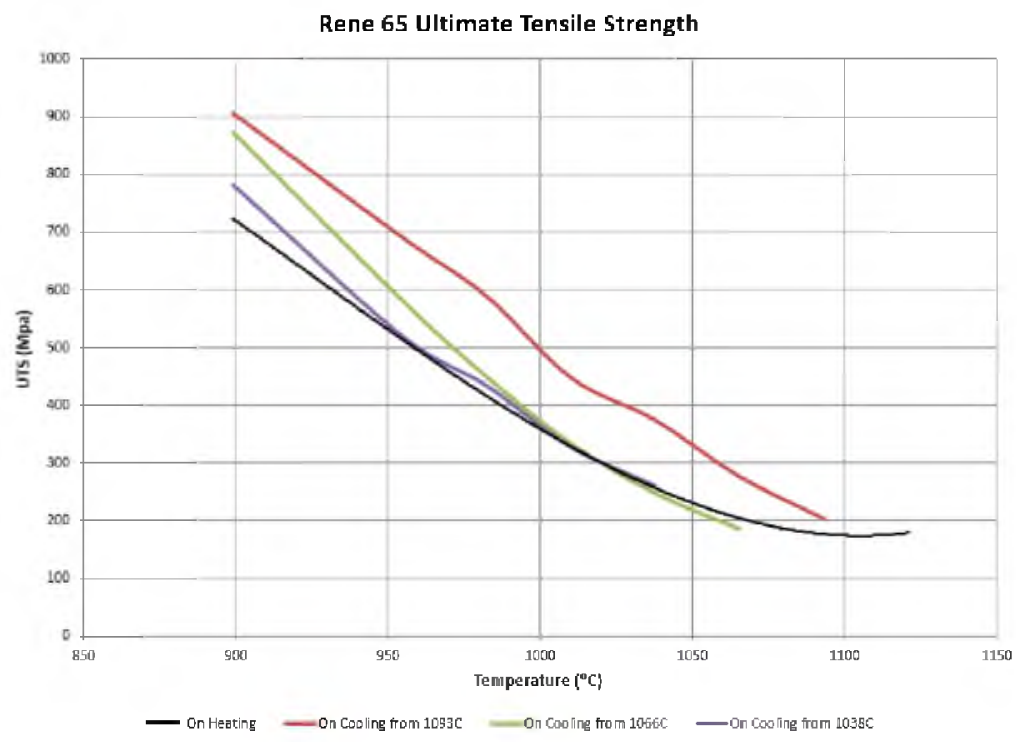

Figure 16. Ultimate Tensile Strength for On Heating and On Cooling Rapid Strain Rate Tests on $254 \mathrm{~mm}$ Dia. Billet of René 65

\section{Conclusions}

General Electric Aviation and ATI Specialty Materials have collaborated to develop a new castwrought superalloy. René 65 is derived from the powder metallurgy alloy René 88DT, but is produced through a triple melt ingot process route, VIM-ESR-VAR. Billetizing is achieved with a combination of open-die press forging and radial forging. As-forged microstructures have been presented for both etched and unetched conditions. Grain coarsening is exhibited at temperatures starting about $1085 \mathrm{C}(1985 \mathrm{~F})$; this must be considered when designing final part thermomechanical processing. To date, hundreds of billets have been successfully produced and the alloy is being widely specified in aircraft engine applications. 


\section{Acknowledgements}

The authors would like to acknowledge the valuable assistance from Dr. Laurence A. Jackman and Dr. A. Stewart Ballantyne in the preparation and completion of this paper, and the metallographic contribution from Shawn Rushing.

\section{References}

1. S.T. Wlodek, M. Kelly, D.A. Alden, The Structure of René 88DT, Superalloys 1996, ed. R.D. Kissinger et. al, TMS.

2. J.M. Moyer, L.A. Jackman, C.B. Adasczik, et. al., Advances in Triple Melting Superalloys 718, 706, and 720, Superalloys 718, 625,706 and Various Derivatives, ed. E.A. Loria, TMS, 1994.

3. B. Shahid and M.C. Thomas, Effect of Interstitial Content on High Temperature Fatigue Crack Propagation and Low Cycle Fatigue of Alloy 720, Superalloys 1992, ed. Antolovich, et. al, TMS.

4. J.A. Heaney, M.L. Lasonde, A.M. Powell, B.J. Bond, C.M. O'Brien, Development of a New Cast and Wrought Alloy (René 65) for High Temperature Disk Applications, Superalloys 718, 625,706 and Various Derivatives, ed. Banik, et al, TMS, 2014.

5. R.S. Minisandram, L.A. Jackman, J.L. Russell, M.L. Lasonde, J.A. Heaney, and A.M. Powell, Recrystallization Response during Thermo-Mechanical Processing of Alloy René 65 Billet, Superalloys 718, 625,706 and Various Derivatives, ed. Banik, et al, TMS, 2014. 